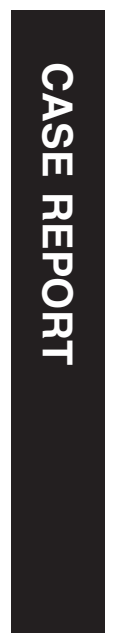

\title{
Unilateral varicella zoster virus ophthalmicus and contralateral acute retinal necrosis
}

\begin{abstract}
We report two patients who developed varicella zoster virus (VZV) ophthalmicus complicated by ipsilateral keratouveitis, and within 4 weeks developed acute retinal necrosis (ARN) in the contralateral eye. The ipsilateral retina was spared in each case.

One patient had systemic lupus erythematosus (SLE) and the other Hodgkin's disease. Both patients were in remission at the time of presentation.

Eye (2002) 16, 778-780. doi:10.1038/

sj.eye. 6700204
\end{abstract}

${ }^{2}$ Department of

Rheumatology

Division of Immunity

and Infection

The University of

Birmingham,

Birmingham, UK

${ }^{3}$ Department of

Ophthalmology

Royal Shrewsbury Hospitals

NHS Trust

Shrewsbury, UK

Correspondence:

Professor PI Murray PhD

FRCS FRCOphth

Academic Unit of

Ophthalmology

Division of Immunity and

Infection

Birmingham and Midland

Eye Centre

City Hospital NHS Trust

Dudley Road

Birmingham B18 7QU, UK

Tel: 01215076851

Fax: 01215076853

E-mail:P.I.Murray@

bham.ac.uk

Received: 19 December

2001

Accepted: 21 March 2002
Keywords: varicella zoster virus; uveitis; acute retinal necrosis; systemic lupus erythematosus; Hodgkin's disease

\section{Case reports}

\section{Case 1}

A 32-year-old Caucasian woman developed right VZV ophthalmicus. Eight years earlier she had been diagnosed with SLE that fulfilled the ARA criteria. SLE had been diagnosed on the basis of arthritis, photosensitivity, haematological and immunological abnormalities, including ANA positivity. She subsequently developed cutaneous vasculitis, myositis, pancreatitis, autoimmune hepatitis, and lupus nephritis. Her acute multisystem SLE was managed with intensive immunosuppression, including pulsed intravenous cyclophosphamide and methylprednisolone. She later developed accelerated hypertension complicated by grade 4 hypertensive retinopathy. This resolved with rigorous treatment of her hypertension. At the
BN Matthews ${ }^{1}, \mathrm{~N} \mathrm{Erb}^{2}, \mathrm{C}$ Gordon², AB Callear ${ }^{3}$, PI Murray ${ }^{1}$ and M Salmon ${ }^{2}$ time of presentation with right VZV ophthalmicus her condition had been stable for 12 months.

She was treated with a 10-day course of oral famciclovir and her other medications included prednisolone $10 \mathrm{mg}$ daily, and azathioprine $100 \mathrm{mg}$ daily. One week later she presented with a painful right eye and reduced vision. On examination, her visual acuities were $6 / 9$ right, 6/6 left and there was a mild right keratouveitis that required topical aciclovir $3 \%$ and prednisolone $0.1 \%$.

Three weeks later, she re-presented with painful loss of vision and floaters in the left eye. Her rash had resolved, the keratouveitis was quiescent but an area of sector iris atrophy was noted. Her left visual acuity was now $6 / 36$ with a left relative afferent pupillary defect, panuveitis, retinal arteritis, inferior retinal necrosis (Figure 1), and a pale optic disc. A diagnosis of ARN syndrome was made. An aqueous humour tap revealed VZV DNA but was negative for CMV, EBV and HSV DNA, using the polymerase chain reaction. She received a 2 -week course of intravenous aciclovir, and underwent prophylactic argon laser photocoagulation.

The necrosis healed and her vision improved to $6 / 9$. She was maintained on long-term oral aciclovir. She subsequently developed a macular epiretinal membrane, retinal detachment, and secondary cataract. Despite successful retinal re-attachment surgery and cataract extraction her vision remained at hand movements. Over a $42-$ month follow-up, her right eye has never developed retinitis, her SLE has been stable, and her immunosuppression unchanged.

Case 2

A 39-year-old Caucasian male presented with left-sided VZV ophthalmicus. The rash 


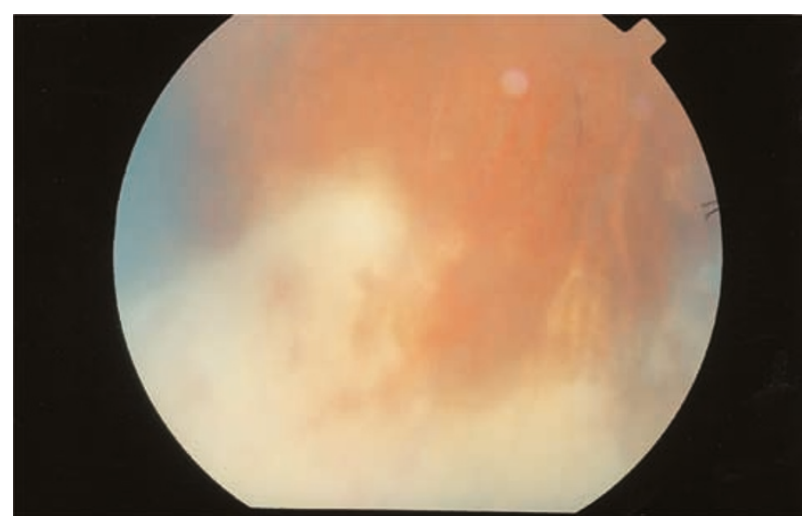

Figure 1 Case 1. Confluent area of retinitis.

involved the tip of his nose. In April 1998 he had been diagnosed with Hodgkin's disease and had undergone a course of radiotherapy. He was currently in remission with normal laboratory markers and CT scans. On examination, his visual acuities were $6 / 6$ in each eye and the only abnormal finding was of a mild left keratouveitis. He was treated with a 10-day course of oral famciclovir, and topical dexamethasone $0.1 \%$ and aciclovir $3 \%$. On review 4 weeks later he complained of reduced vision in his right eye. His visual acuities were 6/12 right, 6/6 left. He had a right panuveitis with multiple Koeppe iris nodules. The right fundus showed three small pale areas in the periphery of the retina that resembled early ARN (Figure 2). The left keratouveitis had resolved. An aqueous humour tap of the right eye detected VZV DNA but was negative for CMV, EBV and HSV DNA, using the polymerase chain reaction.

He underwent a 2-week course of intravenous aciclovir, and prophylactic argon laser photocoagulation. The fundal lesions resolved with no sequelae, and his vision returned to $6 / 6$. He was maintained on oral aciclovir for the next 4 months and has had no recurrence after 15 months of follow-up.

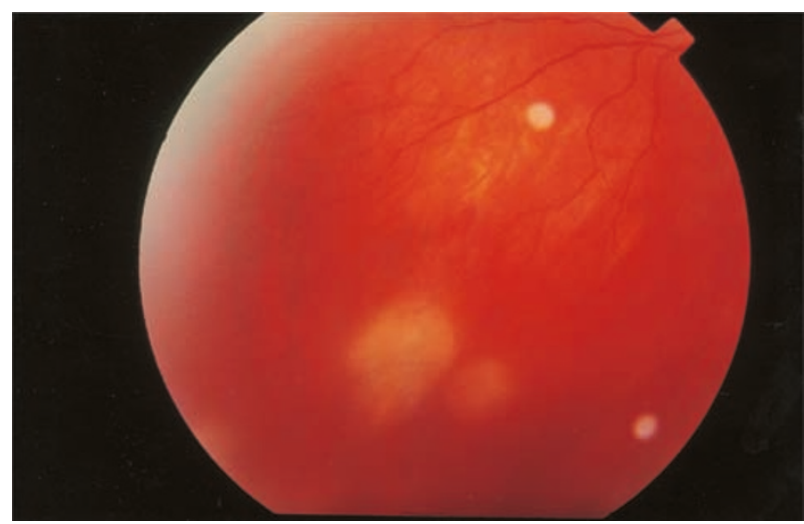

Figure 2 Case 2. Small patch of retinitis.

\section{Comment}

The findings of ipsilateral VZV opthalmicus with contralateral ARN have rarely been reported., ${ }^{1,2}$ Both cases appear to show some similarity with the von Szily animal model, ${ }^{3}$ where inoculation of the KOS strain of herpes simplex virus (HSV) type- 1 into the anterior chamber $(\mathrm{AC})$ of rabbits or mice produces anterior segment inflammation with sparing of the ipsilateral retina, but a severe contralateral necrotising retinitis. Although, in our cases VZV and not HSV was involved and the virus not injected into the $\mathrm{AC}$, there may be similarities in why there is sparing of the ipsilateral retina. In the von Szily model, tracing experiments show that HSV travels from the injected AC to the ipsilateral ciliary ganglion along the parasympathetic fibres of the oculomotor nerve subserving pupillary constriction. From here virus spreads to the ipsilateral suprachiasmatic nucleus (SCN) of the hypothalamus and then travels to the contralateral optic nerve. A T cell-dependent mechanism, requiring either CD4+ or CD8+ cells, appears to stop the spread of virus to the contralateral SCN thus preventing infection of the ipsilateral optic nerve and retina. ${ }^{4}$ The same mechanism might occur with VZV infection in humans.

Both SLE and Hodgkin's disease patients have a higher than normal incidence of VZV infection. SLE patients show depressed cell-mediated but heightened humoral immunity to VZV. Kahl ${ }^{5}$ showed that SLE patients who developed VZV infection were more likely to have experienced serious manifestations of SLE, including nephritis, haemolysis,

thrombocytopaenia, and to have required treatment with cyclophosphamide. Nevertheless, $65 \%$ of infections occurred during mild or inactive SLE when the majority of patients were receiving less than $20 \mathrm{mg}$ of prednisolone daily and no other immunosuppressive therapy, in agreement with our patient.

Hodgkin's disease is associated with a well-described but poorly understood immunological defect. T cells from patients with Hodgkin's disease have defects in signal transduction, including decreased $\mathrm{T}$ cell receptor $\zeta$ chain and decreased tyrosine kinase activation. In addition to anergy, other tests of $\mathrm{T}$ cell function, including responses to mitogens and suppressor cell function, suggest a defect in immune function before and following treatment.

Presumably the immune system of our patients was sufficiently altered to allow infection in the ipsilateral anterior segment and then to the contralateral retina, yet they were subsequently able to mount an adequate $\mathrm{T}$ cell response to prevent spread to the ipsilateral retina. 
Ophthalmologists should be aware of patients with VZV ophthalmicus and contralateral vision loss, as urgent treatment would be required to prevent the potential devastating sight-threatening consequences of the ARN syndrome.

\section{References}

1 Browning DJ, Blumenkranz MS, Culbertson WW et al. Association of varicella zoster dermatitis with acute retinal necrosis syndrome. Ophthalmology 1987; 94: 602606.
2 Farrell TA, Wolf MD, Folk JC et al. Magnetic resonance imaging in a patient with herpes zoster dermatitis and contra-lateral acute retinal necrosis. Am J Ophthalmol 1991; 112: 735-736.

3 von Szily A. An experimental endogenous transmission of infection from bulbus to bulbus. Klin Monatsbl Augenheilkd 1924; 75: 593-602.

4 Azumi A, Atherton SS. Sparing of the ipsilateral retina after anterior chamber inoculation of HSV-1: requirement for either CD4+ or CD8+ T cells. Invest Ophthalmol Vis Sci 1994; 35: 3251-3259.

5 Kahl LE. Herpes zoster infections in systemic lupus erythematosus: risk factors and outcome. J Rheumatol 1994; 21: 84-86. 